FACTA UNIVERSITATIS

Series: Mechanical Engineering Vol. 19, No 3, Special Issue, 2021, pp. 423 - 445

https://doi.org/10.22190/FUME210505053B

Original scientific paper.

\title{
REGIONAL AIRCRAFT SELECTION WITH FUZZY PIPRECIA AND FUZZY MARCOS: A CASE STUDY OF THE TURKISH AIRLINE INDUSTRY
}

\author{
Mahmut Bakır1, Şahap Akan², Emircan Özdemir ${ }^{3}$ \\ ${ }^{1}$ Samsun University, Samsun, Turkey \\ ${ }^{2}$ Anadolu University, Eskişehir, Turkey \\ ${ }^{3}$ Eskişehir Technical University, Eskişehir, Turkey
}

\begin{abstract}
Aircraft selection is an important issue in achieving long-term goals in the airline industry. For this issue in which multiple conflicting criteria are involved, the extant literature points to the use of multi-criteria decision-making (MCDM) methods. In this respect, this study aims to propose a systematic and comprehensive framework with a focus on the regional aircraft selection perspective. To achieve this, an integrated fuzzy Pivot Pairwise Relative Criteria Importance Assessment (FPIPRECIA) and fuzzy Measurement Alternatives and Ranking according to the Compromise Solution (F-MARCOS) approach was employed. In this study, in which six regional aircraft alternatives were evaluated according to 14 criteria, data were collected from five decision experts. As a result, it was found that the most pivotal criterion is C33 (Operational Cost), and the least important criterion is C12 (NOx). In addition, CRJ1000 was identified as the most promising regional aircraft alternative. The results of the application were further validated by applying a three-stage sensitivity analysis. The proposed structure is anticipated to assist airline managers in aircraft selection decisions under uncertainty by offering a robust and systematic tool.
\end{abstract}

Key Words: Fuzzy Sets Theory, PIPRECIA, MARCOS, Regional Aircraft Selection, Passenger Perceptions

\section{INTRODUCTION}

The airline industry has been growing steadily since deregulation, and this trend is expected to continue in the future [1]. Accordingly, the number of passengers, which was 4.5 billion in 2019 , is projected to rise to 8 billion by 2039 [2]. Similarly, ICAO [3] predicts that the number of passengers may reach 10 billion by 2040 . This development

Received May 05, 2020 / Accepted July 10, 2021

Corresponding author: Mahmut Bakır

Samsun University, School of Civil Aviation, Ballica Campus 55420, Samsun, Turkey

E-mail: mahmut.bakir@samsun.edu.tr 
in the airline industry covers a wide range of potential customers. Passengers living in remote areas with relatively low populations are also one of these potential customer groups. It should be ensured that these passengers are transported to the hub airports or to various destinations via the hub airports. Moreover, airline service should be provided from these regions to destinations with high passenger potential through point-to-point flights. At this point, regional airlines come to the fore, and it is regarded that regional aviation is a suitable business model for providing airline services to the aforementioned target group [4].

Regional airlines must make some decisions to match the increasing passenger demand with airline capacity in current market conditions. One of these decisions is to select the most suitable aircraft types in line with their strategies [5]. However, it is challenging for airline managers to make such complex decisions. This difficulty stems from the fact that choosing the appropriate aircraft type often depends on taking into account a large number of conflicting criteria that are difficult to assess simultaneously [5,6].

There are many factors that need to be considered when selecting regional aircraft, both from airline and passenger perspectives. In terms of airline management, factors such as suitable payment terms, inclusion in the fleet at the right time, and the low operational cost come to the fore. From the passenger perspective, factors such as the appropriate schedule, flight comfort, and service quality are important. Therefore, not only operational factors should be taken into consideration in regional aircraft selection, but these factors should also be evaluated together with passenger expectations. In addition, the environmental impact of the aircraft to be selected and their compliance with governments' policies need to be considered [7]. In this context, airlines should consider all factors and make the optimum choice according to their business model, customer profile, and strategies [8]. However, aircraft selection relies on different criteria, while some of them can be expressed numerically and others can be described qualitatively [8]. Therefore, it is crucial to employ an appropriate methodological approach to the problem of aircraft selection.

The extant literature suggests the use of MCDM methods in aircraft selection [5, 9]. MCDM methods are tools that allow decision-makers (DMs) to make appropriate choices in complex decision problems where there are several conflicting criteria $[10,11]$. On the other hand, it should be noted that human judgments are often uncertain and ambiguous [9]. For this reason, MCDM methods are often adapted to fuzzy sets theory to deal with subjective and qualitative judgments under uncertainty [12]. Given that aircraft selection is an MCDM problem involving a large number of subjective criteria, this present study aims at proposing a systematic and comprehensive framework for regional aircraft selection. Another specific purpose of this study is to examine the applicability of the proposed framework in the context of the Turkish airline industry. To this end, an integrated F-PIPRECIA and F-MARCOS approach was employed.

There are a few motivations behind this study. Firstly, given the increasing passenger demand [2] and the anticipated need for regional aircraft in the next 15 years [13], it is clear that the regional airline business model will show great development. Therefore, the problem of aircraft selection, which is strategically important for regional airlines, is worth investigating. However, there is a paucity of studies in the literature specifically examining regional aircraft selection $[7,8]$. Secondly, previous research addressing the aircraft selection problem has mainly focused on technical, operational [5, 8], or environmental [7] criteria. In addition to these criteria, this study also considers the passenger perspective criteria. Thirdly, the airline industry in Turkey has grown dramatically in the last two decades [14]. In this 
regard, it is anticipated that this study will provide valuable insights to airline managers regarding the development of regional transportation in Turkey. This study provides a few contributions to the existing literature: a) a systematic and comprehensive framework is proposed for regional aircraft selection, b) this is the first study to investigate regional aircraft selection in Turkey, and, c) the robustness of the application is achieved through a rigorous three-stage sensitivity analysis.

The remainder of the paper is structured as follows. Section 2 provides further information about the extant literature on regional airlines and aircraft selection criteria. Then, Section 3 details the step-by-step procedures of the proposed methodology. Section 4 begins by explaining the proposed framework and then presents an empirical study with sensitivity analysis. Finally, Section 5 provides a summary of the study's results, implications, limitations, and directions for future research.

\section{LITERATURE REVIEW}

\subsection{Regional aviation activities}

Regional airlines are of great importance to communities in rural and remote areas. Airlines operating in this business model contribute to economic and social development by connecting low population settlements to air transportation hubs. They represent a critical lifeline for stakeholders in these areas [15]. This business model of critical importance in the airline industry has undergone some changes over time. As a result of these changes, different definitions have been made for this airline business model. In the previous definitions, regional airlines were defined as airlines with lower seat capacity (up to 90), but their seat capacity has increased even more over time [4]. Especially, after aircraft manufacturers such as Embraer started to produce regional jet aircraft with a capacity of 120 seats, the definition of the regional airline has expanded [16]. In this study, regional airlines are considered as short-haul scheduled carriers with seat capacity below 120 .

Nowadays, regional airlines operate in different ways of business strategy. The first of these is that the regional airlines operate under code share agreements with one or more major carriers [17]. The second group is that they operate independently with their own flight code [18]. Regional airlines have a characteristic that feeds hubs in both business strategies. They operate mostly in countries with high GDP. It is predicted that regional aviation will also become more widespread in developing countries in the forthcoming years. Embraer [13] stated that there would be a need for 10,550 regional jets worldwide between 2019-2038, and the demand for regional jets in certain parts of the world would increase. Therefore, one of the important research areas on regional airlines has been identified as the problem of aircraft selection. It is anticipated that such studies will provide valuable contributions to the stakeholders of the airline industry.

\subsection{Aircraft selection problem}

Airline managers have to make many decisions in order to fulfill a number of timeconstrained processes due to the nature of their work. These cover a wide range from simple procedural decisions to large investment decisions. One of the risky investment decisions is aircraft selection, which can affect the sustainability and competitive ability of airlines [19]. Aircraft selection problem, which has a quite high investment amount, is 
a process that is affected by many different factors such as business strategies, passenger needs, government policies [7]. Therefore, optimum decisions should be made for the airline by considering all factors. At this point, a number of tools that enable DMs to make effective and efficient decisions are highly beneficial. Due to the multiple criteria nature of the aircraft selection problem, MCDM techniques come to the fore in this regard [19]. MCDM techniques have been frequently used in aircraft selection problems in the aviation industry. In the past studies, many selection problems on fighter jet [20, 21], aerobatics aircraft [22], training aircraft [23, 24], and commercial aircraft [7, 8, 25, 26] have been handled with these techniques. In addition, cargo aircraft [27], long-haul aircraft [28], medium-haul aircraft [9, 25, 29], and short-haul aircraft [26] selection studies have been conducted by detailing the aircraft selection problem. Methodologically, prior research employed numerous techniques, including AHP and TOPSIS in interval type-2 fuzzy sets [9], fuzzy AHP [7, 8, 26], fuzzy TOPSIS [23, 30], fuzzy AHP and TOPSIS [24], AHP and even swaps method (ESM) [5], SWARA and SMAA-2 method [22], an integrated AHP, COPRAS, and MOORA methodology [25], fuzzy AHP and fuzzy grey relational analysis (GIA) [27], linear physical programming [19], AHP [20], NAIADE (Novel Approach to Imprecise Assessment and Decision Environments) [31], FUCOM and ARAS [21], fuzzy AHP and fuzzy ANP [29], ELECTRE, SAW, and TOPSIS [28], ANP [32], and fuzzy reference ideal method (FRIM) [33]. In Table 1, the aircraft selection literature is depicted by detailing research purposes and criteria sets.

The problem of aircraft selection in regional airlines has found a limited area in the literature. Ahmed et al. [7] addressed an aircraft selection problem of regional airlines in Canada. It has addressed the aircraft selection problem of regional airlines in Canada by focusing on the sustainability issue. Bruno et al. [26] used a hybrid approach based on AHP and fuzzy set theory in order to evaluate jet engine regional aircraft alternatives. Dožić and Kalić [5] conducted a study limited to six criteria using AHP and ESM methods. In a similar study, Dožić et al. [8] mainly focused on technical and economic factors among aircraft alternatives by using fuzzy AHP. Gomes et al. [31] used the NAIADE method for regional aircraft selection problem using aircraft alternatives with up to 26 seats. When the studies conducted are evaluated in general, the methods used, criteria, and aircraft alternatives differ from each other. In terms of methodology, fuzzy AHP was predominantly used in the studies. However, as the number of criteria increases in the fuzzy AHP, the number of binary comparisons increases, so consistency problem may occur [34]. Therefore, we believe that there is a need for methods that will provide more consistent and robust results in regional aircraft selection problems.

In terms of the criteria, it can be stated that different approaches were adopted in previous studies. Accordingly, some studies mainly focused on economical and technical criteria, while some studies focused on today's important issues such as sustainability. Hence, putting forward a comprehensive framework that includes many criteria may be an important contribution to the existing literature. In terms of aircraft alternatives used and their seat capacities, quite different aircraft engine types (e.g., turbojet and turboprop engines) and various seat capacities were evaluated in the past. Therefore, it is necessary to consider quite wide and different aircraft options with low and high seat capacity, considering different needs. Consequently, this study, which focuses on regional aircraft selection, taking into account the limitations mentioned above and focuses on the perspective of the Turkish airline industry. In doing so, using a comprehensive set of criteria shown in 
Fig. 2, an integrated F-PIPRECIA and F-MARCOS approach has been adopted that can yield powerful results methodologically.

Table 1 Aircraft selection criteria in the literature

\begin{tabular}{|c|c|c|c|c|c|c|c|c|c|c|c|c|c|c|c|}
\hline Author(s) & $\begin{array}{l}\stackrel{0}{0} \\
.00 \\
\frac{0}{0} \\
0\end{array}$ & 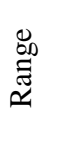 & $U$ & $\begin{array}{l}\text { D्ठ } \\
\text { ڤ } \\
\text { क }\end{array}$ & $\begin{array}{l}3 \\
\vdots \\
\sum \\
\sum\end{array}$ & $\stackrel{U}{\Sigma}$ & ৩઼ & $\stackrel{2}{4}$ & $\ddot{2}$ & $\stackrel{\varrho}{\circlearrowright}$ & $\stackrel{\theta}{s}$ & $\underset{\Downarrow}{\ll}$ & $\overbrace{}^{N}$ & $\stackrel{\swarrow}{ٍ}$ & $\frac{\mathscr{n}}{0}$ \\
\hline Bruno et al. [26] & $\mathrm{R}$ & & & $\cdot$ & & & $\cdot$ & $\cdot$ & & $\cdot$ & & & $\cdot$ & & $\cdot$ \\
\hline Kiracı \& Akan [9] & $\mathrm{C}$ & & $\cdot$ & & $\cdot$ & & $\cdot$ & - & $\cdot$ & & & & $\cdot$ & & $\cdot$ \\
\hline Wang \& Chang [23] & $\mathrm{T}$ & & & $\cdot$ & & & & & & & & & & & \\
\hline Dožić et al. [8] & $\mathrm{R}$ & $\cdot$ & $\cdot$ & & & $\cdot$ & & $\cdot$ & & $\cdot$ & & & & & \\
\hline Sánchez-Lozano et al. [24] & $\mathrm{T}$ & & & $\cdot$ & & & $\cdot$ & & & & & & & & \\
\hline Dožić \& Kalić [5] & $\mathrm{R}$ & & $\cdot$ & & $\cdot$ & & & - & & & & & & & \\
\hline Durmaz \& Gencer [22] & A & & & & & & & & & & & & & & \\
\hline Kiracı \& Bakır [25] & $\mathrm{C}$ & $\cdot$ & $\cdot$ & $\cdot$ & & & $\cdot$ & $\cdot$ & & & & & & & \\
\hline Akyurt \& Kabadayı [27] & $\mathrm{Ca}$ & $\cdot$ & & & & $\cdot$ & & $\cdot$ & $\cdot$ & & & & & & \\
\hline Ahmed et al. [7] & $\mathrm{R}$ & & & & & & & & & $\cdot$ & & & $\cdot$ & $\cdot$ & $\cdot$ \\
\hline Ilgin [19] & $\mathrm{C}$ & $\cdot$ & $\cdot$ & & & & $\cdot$ & $\cdot$ & & & & & & & \\
\hline Ali et al.[20] & $\mathrm{F}$ & & & $\cdot$ & $\cdot$ & $\cdot$ & $\cdot$ & $\cdot$ & & & & & & & \\
\hline Gomes et al. [31] & $\mathrm{R}$ & - & & $\cdot$ & & & $\cdot$ & $\cdot$ & & & $\cdot$ & & & & \\
\hline Van Hoan \& Ha [21] & $\mathrm{F}$ & & & $\cdot$ & $\cdot$ & & $\cdot$ & $\cdot$ & & & $\cdot$ & & & & \\
\hline Ozdemir \& Basligil [29] & $\mathrm{C}$ & & & & & $\cdot$ & $\cdot$ & - & $\cdot$ & & - & & & & \\
\hline Sun et al. [28] & $\mathrm{C}$ & & $\cdot$ & $\cdot$ & $\cdot$ & & $\cdot$ & & & & & & & & \\
\hline Yeh \& Chang [30] & $\mathrm{C}$ & $\cdot$ & & & & & $\cdot$ & $\cdot$ & & & & & & & $\cdot$ \\
\hline Ozdemir et al.[32] & $\mathrm{C}$ & & & & & $\cdot$ & $\cdot$ & - & $\cdot$ & & $\cdot$ & & & & \\
\hline $\begin{array}{l}\text { Sánchez-Lozano \& Rodríguez } \\
\text { [33] }\end{array}$ & $\mathrm{T}$ & $\cdot$ & & $\cdot$ & & & & $\cdot$ & & & & & & & \\
\hline Our proposed framework & $\mathrm{R}$ & - & $\cdot$ & $\cdot$ & $\cdot$ & $\cdot$ & $\cdot$ & $\cdot$ & - & - & $\cdot$ & $\cdot$ & - & - & $\cdot$ \\
\hline
\end{tabular}

\section{Methodology}

\subsection{Preliminaries of fuzzy sets}

Many real-world examples include ambiguity and vagueness that cannot be articulated precisely. Zadeh [35] proposed the Fuzzy sets theory to express and model such uncertainties more partially. Within the scope of fuzzy sets, the membership function $\boldsymbol{\mu}_{\tilde{F}}(x): R \rightarrow[0,1]$ of a triangular fuzzy number (TFN) $\tilde{F}$ is found as follows [36]. 


$$
\boldsymbol{\mu}_{\tilde{F}}(x)=\left\{\begin{array}{cc}
0, & x<l \\
\frac{x-l}{m-l}, & l \leq x \leq m \\
\frac{u-x}{u-m}, & m \leq x \leq u \\
0, & x>u
\end{array}\right.
$$

From Eq. (1), $l$ and $u$ represent the lower and upper bounds of fuzzy number $\tilde{F}$, and $m$ shows the most promising value of $\tilde{F}$. If we consider that $\tilde{F}=\left(l_{1}, m_{1}, u_{1}\right)$ and $\tilde{K}=\left(l_{2}, m_{2}, u_{2}\right)$ are two TFNs, the basic operations for the TFNs are given below [37, 38]:

$$
\begin{gathered}
\tilde{F} \oplus \tilde{K}=\left(l_{1}, m_{1}, u_{1}\right)+\left(l_{2}, m_{2}, u_{2}\right)=\left(l_{1}+l_{2}, m_{1}+m_{2}, u_{1}+u_{2}\right) \\
\tilde{F} \otimes \tilde{K}=\left(l_{1}, m_{1}, u_{1}\right) \otimes\left(l_{2}, m_{2}, u_{2}\right)=\left(l_{1} \times l_{2}, m_{1} \times m_{2}, u_{1} \times u_{2}\right) \\
\tilde{F}-\tilde{K}=\left(l_{1}, m_{1}, u_{1}\right)-\left(l_{2}, m_{2}, u_{2}\right)=\left(l_{1}-u_{2}, m_{1}-m_{2}, u_{1}-l_{2}\right) \\
\frac{\tilde{F}}{\tilde{K}}=\frac{\left(l_{1}, m_{1}, u_{1}\right)}{\left(l_{2}, m_{2}, u_{2}\right)}=\left(\frac{l_{1}}{u_{2}}, \frac{m_{1}}{m_{2}}, \frac{u_{1}}{l_{2}}\right) \\
\tilde{F}_{1}^{-1}=\left(l_{1}, m_{1}, u_{1}\right)^{-1}=\left(\frac{1}{u_{1}}, \frac{1}{m_{1}}, \frac{1}{l_{1}}\right)
\end{gathered}
$$

Let us assume again that $\tilde{F}=\left(l_{l}, m_{l}, u_{l}\right)$ is a TFN. The defuzzified (crisp) value of $\tilde{F}$ can be obtained as follows [39]:

$$
d f_{\text {crisp }}=\frac{l+4 m+u}{6}
$$

\subsection{F-PIPRECIA method}

The PIPRECIA method is derived from the SWARA method to measure the cognitive attitudes of DMs [40]. The PIPRECIA approach is beneficial for group decisions involving a large number of criteria or experts, as it decreases the cognitive burden of DMs by reducing pairwise comparisons. The PIPRECIA method has been extended to fuzzy numbers by Stević et al. [11] to handle ambiguous judgments more effectively.

The F-PIPRECIA method has existed in many successful applications in the literature. Stević et al. [11] introduced the F-PIPRECIA method for the barcode technology implementation case. Furthermore, this approach has been successfully applied in many areas, including selecting reach stacker [41], road transportation risk analysis [42], green supplier selection [43], determining the safety level in railway crossings [44], and the highperformance computing problem [45]. The F-PIPRECIA method needs the following steps for calculation [11]:

Step 1 Identify the DMs and define the criteria to be used. DMs rank criteria from first to last, regardless of the significance of the criteria. 
Step 2 Starting with the second criterion, DMs evaluate the criteria in order to obtain the relative importance of the criteria.

$$
\tilde{s}_{j}^{r}=\left\{\begin{array}{lll}
>\tilde{1} & \text { if } & C_{j}>C_{j-1} \\
=\tilde{1} & \text { if } & C_{j}=C_{j-1} \\
<\tilde{1} & \text { if } & C_{j}<C_{j-1}
\end{array}\right.
$$

where $\tilde{s}_{j}^{r}$ denotes the evaluation of the criteria by decision-maker $r$. To construct a matrix $\tilde{s}_{j}$, the geometric mean of matrix $\tilde{s}_{j}^{r}$ has to be calculated. DMs use the linguistic scales in Table 2 and Table 3 when evaluating the criteria compared to the previous criteria [11].

Table 2 The scale 1-2 for the evaluation of the criteria

\begin{tabular}{|c|c|c|c|c|c|}
\hline Linguistic terms & & 1 & $\mathrm{~m}$ & $\mathrm{u}$ & DFV \\
\hline Almost equally important & & 1.000 & 1.000 & 1.050 & 1.008 \\
\hline Weakly more important & & 1.100 & 1.150 & 1.200 & 1.150 \\
\hline Moderately more important & & 1.200 & 1.300 & 1.350 & 1.292 \\
\hline More important & Scale 1-2 & 1.300 & 1.450 & 1.500 & 1.433 \\
\hline Strongly more important & & 1.400 & 1.600 & 1.650 & 1.575 \\
\hline Very strongly more important & & 1.500 & 1.750 & 1.800 & 1.717 \\
\hline Absolutely more important & & 1.600 & 1.900 & 1.950 & 1.858 \\
\hline
\end{tabular}

Table 3 The scale 0-1 for the evaluation of the criteria

\begin{tabular}{ccccll}
\hline & $\mathrm{l}$ & $\mathrm{m}$ & $\mathrm{u}$ & $\mathrm{DFV}$ & Linguistic terms \\
\hline & 0.667 & 1.000 & 1.000 & 0.944 & Weakly less important \\
& 0.500 & 0.667 & 1.000 & 0.694 & Moderately less important \\
Scale 0-1 & 0.400 & 0.500 & 0.667 & 0.511 & Less important \\
& 0.333 & 0.400 & 0.500 & 0.406 & Really less important \\
& 0.286 & 0.333 & 0.400 & 0.337 & Strongly less important \\
& 0.250 & 0.286 & 0.333 & 0.288 & Very strongly less important \\
& 0.222 & 0.250 & 0.286 & 0.251 & Absolutely less important \\
\hline
\end{tabular}

If the marked criterion is more important than the previous one, the evaluations are completed by following Table 2 . Conversely, if the marked criterion is less important than the previous one, the linguistic expressions in Table 3 are adopted. The tables also include defuzzified values (DFV) of each comparison, making it easier for DMs to evaluate [11].

Step 3 Calculate coefficient $\tilde{k}_{j}$.

$$
\tilde{k}_{j}=\left\{\begin{array}{lll}
=\tilde{1} & \text { if } & j=1 \\
2-\tilde{s}_{j} & \text { if } & j>1
\end{array}\right.
$$

Step 4 Determine fuzzy weight $\tilde{q}_{j}$.

$$
\tilde{q}_{j}=\left\{\begin{array}{lll}
=\tilde{1} & \text { if } & j=1 \\
\frac{\tilde{q}_{j-1}}{\tilde{k}_{j}} & \text { if } & j>1
\end{array}\right.
$$


Step 5 Obtain the relative weight of criteria $\tilde{w}_{j}$.

$$
\tilde{w}_{j}=\frac{\tilde{q}_{j}}{\sum_{j=1}^{n} \tilde{q}_{j}}
$$

The F-PIPRECIA approach dictates the use of the inverse methodology after assigning coefficients $\tilde{w}_{j}$.

Step 6 To provide inverse pairwise comparisons, the evaluation is performed starting with a penultimate criterion in this round.

$$
\tilde{s}_{j}^{r^{\prime}}=\left\{\begin{array}{lll}
>\tilde{1} & \text { if } & C_{j}>C_{j+1} \\
=\tilde{1} & \text { if } & C_{j}=C_{j+1} \\
<\tilde{1} & \text { if } & C_{j}<C_{j+1}
\end{array}\right.
$$

where $\tilde{s}_{j}^{r^{\prime}}$ represents the evaluation of criteria made by a decision-maker $r$. It is again necessary to aggregate the inverse comparison values by means of the geometric mean.

Step 7 Determine coefficient $\tilde{k}_{j}^{\prime}$.

$$
\tilde{k}_{j}^{\prime}=\left\{\begin{array}{lll}
=\tilde{1} & \text { if } & j=n \\
2-\tilde{s}_{j}^{\prime} & \text { if } & j>n
\end{array}\right.
$$

Step 8 Determine fuzzy weight $\tilde{q}_{j}^{\prime}$.

$$
\tilde{q}_{j}^{\prime}=\left\{\begin{array}{lll}
=\tilde{1} & \text { if } & j=n \\
\frac{\tilde{q}_{j+1}{ }^{\prime}}{\tilde{k}_{j}^{\prime}} & \text { if } & j>n
\end{array}\right.
$$

Step 9 Obtain the relative weight of criteria $\tilde{w}_{j}^{\prime}$.

$$
\tilde{w}_{j}^{\prime}=\frac{\tilde{q}_{j}^{\prime}}{\sum_{j=1}^{n} \tilde{q}_{j}^{\prime}}
$$

Step 10 Fuzzy values $\tilde{w}_{j}$ and $\tilde{w}_{j}^{\prime}$ should be defuzzified in order to achieve the final weights of criteria $\tilde{w}_{j}^{\prime \prime}$.

$$
\tilde{w}_{j}^{\prime \prime}=\frac{1}{2}\left(w_{j}+w_{j}^{\prime}\right)
$$

Step 11 Using Spearman's rank correlation coefficient (SRC), the consistency of the weights is confirmed in the final step. 


\subsection{F-MARCOS method}

The MARCOS method by Stević et al. [46] is a utility function-based MCDM method. The basic computational principle of the technique relies on the ideal (ID) and anti-ideal $(A I)$ solutions. Accordingly, it takes into account the relationships between ideal and anti-ideal points and alternatives [37, 47]. The MARCOS method, like the TOPSIS method, defines the alternative that is nearest to the ideal point and farthest from the anti-ideal point as the best-ranked solution [48, 49]. Stanković et al. [37] introduced the F-MARCOS methodology to provide more precise results in an uncertain environment. This extended version both overcomes uncertainty and gives more stable results in larger decision-making matrices [37].

The F-MARCOS approach was first used to analyze road traffic risk in the literature [37]. Following this, it has been successfully applied in many studies such as determining the level of safety on the roads [50], selecting sustainable suppliers [48], evaluating the competitiveness of spa centers [47], and evaluating the safety levels of railway crossings [44]. The F-MARCOS method includes the following steps [47, 48]:

Step 1 Construct the initial fuzzy decision matrix. As with other MCDM techniques, a decision matrix is constructed in which the $m$ alternatives and $n$ criteria are present. Table 4 can be used for DMs to evaluate alternatives [47, 48].

Table 4 The linguistic scale for rating of the alternatives

\begin{tabular}{lc}
\hline Linguistic terms & TFNs \\
\hline Very Poor & $(0,0,1)$ \\
Poor & $(0,1,3)$ \\
Medium poor & $(1,3,5)$ \\
Medium & $(3,5,7)$ \\
Medium good & $(5,7,9)$ \\
Good & $(7,9,10)$ \\
Very good & $(9,10,10)$ \\
\hline
\end{tabular}

Step 2 Extent the initial fuzzy decision matrix. The initial decision matrix is extended by adding fuzzy ideal $\tilde{A}(I D)$ and fuzzy anti-ideal $\tilde{A}(A I)$ solutions. While $\tilde{A}(I D)$ indicates the most desirable alternative, $\tilde{A}(A I)$ indicates the most undesirable one. Considering the type of criteria, solutions $\tilde{A}(I D)$ and $\tilde{A}(A I)$ are found as follows.

$$
\begin{aligned}
& \tilde{A}(A I)=\min _{i} \tilde{x}_{i j} \text { if } j \in B \text { and } \max _{i} \tilde{x}_{i j} \text { if } j \in C \\
& \tilde{A}(I D)=\max _{i} \tilde{x}_{i j} \text { if } j \in B \text { and } \min _{i} \tilde{x}_{i j} \text { if } j \in C
\end{aligned}
$$

where $B$ represents the maximization type criteria and $C$ represents the minimization type criteria.

Step 3 Formulate the normalized fuzzy decision matrix. The elements of the decision matrix including solutions $\tilde{A}(I D)$ and $\tilde{A}(A I)$ are standardized.

$$
\tilde{n}_{i j}=\left(n_{i j}^{l}, n_{i j}^{m}, n_{i j}^{u}\right)=\left(\frac{x_{i d}^{l}}{x_{i j}^{u}}, \frac{x_{i d}^{l}}{x_{i j}^{m}}, \frac{x_{i d}^{l}}{x_{i j}^{l}}\right) \text { if } j \in C
$$




$$
\tilde{n}_{i j}=\left(n_{i j}^{l}, n_{i j}^{m}, n_{i j}^{u}\right)=\left(\frac{x_{i j}^{l}}{x_{i d}^{u}}, \frac{x_{i j}^{m}}{x_{i d}^{u}}, \frac{x_{i j}^{u}}{x_{i d}^{u}}\right) \text { if } j \in B
$$

where elements $x_{i j}^{l}, x_{i j}^{m}, x_{i j}^{u}$ come from Step 1, and $x_{i d}^{l}, x_{i d}^{u}$ are retrieved from $\tilde{A}(I D)$.

Step 4 Construct the weighted fuzzy decision matrix. Normalized values are multiplied by the weight coefficients, thus obtaining matrix $\tilde{V}$.

$$
\tilde{v}_{i j}=\tilde{n}_{i j} \otimes \tilde{w}_{i j}=\left(n_{i j}^{l} \times \tilde{w}_{j}^{l}, n_{i j}^{m} \times \tilde{w}_{j}^{m}, n_{i j}^{u} \times \tilde{w}_{j}^{u}\right)
$$

Step 5 Obtain fuzzy summation matrix $\left(\tilde{S}_{i}\right)$. The row elements of the weighted fuzzy decision matrix are summed.

$$
\tilde{S}_{i}=\sum_{i=1}^{n} \tilde{v}_{i j}
$$

Step 6 Calculate the utility degrees of the alternatives. Matrices $\tilde{K}_{i}^{-}$and $\tilde{K}_{i}^{+}$are constructed according to the total values of ideal and anti-ideal solutions.

$$
\begin{aligned}
& \tilde{K}_{i}^{-}=\frac{\tilde{S}_{i}}{\tilde{S}_{a i}}=\left(\frac{s_{i}^{l}}{s_{a i}^{u}}, \frac{s_{i}^{m}}{s_{a i}^{m}}, \frac{s_{i}^{u}}{s_{a i}^{l}}\right) \\
& \tilde{K}_{i}^{+}=\frac{\tilde{S}_{i}}{\tilde{S}_{i d}}=\left(\frac{s_{i}^{l}}{s_{i d}^{u}}, \frac{s_{i}^{m}}{s_{i d}^{m}}, \frac{s_{i}^{u}}{s_{i d}^{l}}\right)
\end{aligned}
$$

Step 7 Create fuzzy matrix $\tilde{T}_{i}$.

$$
\tilde{T}_{i}=\tilde{t}_{i}=\left(t_{i}^{l}+t_{i}^{m}, t_{i}^{u}\right)=\tilde{K}_{i}^{-} \oplus \tilde{K}_{i}^{+}=\left(k_{i}^{-l}+k_{i}^{+l}, k_{i}^{-m}+k_{i}^{+m}, k_{i}^{-u}+k_{i}^{+u}\right)
$$

Then a new fuzzy number $(\tilde{D})$ is derived from the elements of matrix $\tilde{T}_{i}$.

$$
\tilde{D}=\left(d^{l}, d^{m}, d^{u}\right)=\max _{i} \tilde{t}_{i j}
$$

Then, fuzzy number $\tilde{D}$ is defuzzified using Eq. (7), yielding $d f_{\text {crisp }}$.

Step 8 Identify utility functions of alternatives. Using number $d f_{\text {crisp }}$, solutions $f\left(\tilde{K}_{i}^{+}\right)$ and $f\left(\tilde{K}_{i}^{-}\right)$are created from the results of Step 6.

$$
\begin{aligned}
& f\left(\tilde{K}_{i}^{+}\right)=\frac{\tilde{K}_{i}^{-}}{d f_{\text {crisp }}}=\left(\frac{k_{i}^{-l}}{d f_{\text {crisp }}}, \frac{k_{i}^{-m}}{d f_{\text {crisp }}}, \frac{k_{i}^{-u}}{d f_{\text {crisp }}}\right) \\
& f\left(\tilde{K}_{i}^{-}\right)=\frac{\tilde{K}_{i}^{+}}{d f_{\text {crisp }}}=\left(\frac{k_{i}^{+l}}{d f_{\text {crisp }}}, \frac{k_{i}^{+m}}{d f_{\text {crisp }}}, \frac{k_{i}^{+u}}{d f_{\text {crisp }}}\right)
\end{aligned}
$$

At this step, a defuzzification procedure must be applied for each of $\tilde{K}_{i}^{-}, \tilde{K}_{i}^{+}$, $f\left(\tilde{K}_{i}^{-}\right)$and $f\left(\tilde{K}_{i}^{+}\right)$.

Step 9 Create final utility function $f\left(K_{i}\right)$. 


$$
f\left(K_{i}\right)=\frac{K_{i}^{+}+K_{i}^{-}}{1+\frac{1-f\left(K_{i}^{+}\right)}{f\left(K_{i}^{+}\right)}+\frac{1-f\left(K_{i}^{-}\right)}{f\left(K_{i}^{-}\right)}}
$$

It should be noted that the most optimal alternative is the one with the highest utility function $f\left(K_{i}\right)$.

\section{EMPIRICAL STUDY FOR THE TURKISH AIRLINE INDUSTRY}

After the liberalization of the aviation market in 2003 in Turkey, the number of major components in the aviation system such as airlines and airports has increased rapidly [51]. By increasing passenger accessibility and lowering ticket prices, the number of passengers on domestic flights has increased significantly [52]. The main distinguishing feature of regional airlines compared to other airline business models is that they connect small communities to different destinations with short and medium-distance domestic flights [53]. Today, domestic passenger demand in Turkey still maintains its increasing trend. Therefore, future fleet planning studies of regional airlines are important. The aircraft selection problem, which is included in the fleet planning activities of regional airlines, is a strategic decision that is extremely effective in the success of airlines. In the study, the regional aircraft selection problem for the Turkish airline industry has been addressed using the F-PIPRECIA and F-MARCOS methods.

\subsection{Framework for the regional aircraft selection}

The study is divided into four phases, as shown in Fig. 1. The first of these is the preparatory stage. The second stage is the F-PIPRECIA application, where regional aircraft selection criteria weights are calculated. The third stage is the F-MARCOS application, where alternative regional aircraft types are ranked. In the fourth and last stage, a three-stage rigorous sensitivity analysis of the empirical study is given.

In the first step of Phase I, the research problem was determined as selecting aircraft type for the regional airlines in Turkey. Instead of specifying an airline company for aircraft selection, the regional airline business model is tackled within the scope of the Turkish airline industry characteristics. The solution to be produced in this context is intended to be suitable for all regional airline activities in Turkey. Considering the aircraft selection literature and regional aviation characteristics in Turkey, four main criteria that are effective in regional aircraft selection have been determined: technical performance, economical performance, passenger perception, and environmental impact. Technical performance, economical performance, and environmental impact criteria have been addressed in many previous aircraft selection studies [7, 26, 31, 54]. To the best of the authors' knowledge, no previous study has discussed aircraft selection problem by addressing the passenger perception criterion. On the other hand, it is well-established that the aircraft body appearance [55], cabin interior design [56], and safety-related factors $[31,57,58]$, which are directly related to the aircraft type, have an effect on the perception of the passengers. For this reason, passenger perception is an important criterion to be taken into consideration in the selection of aircraft type of regional airlines. 


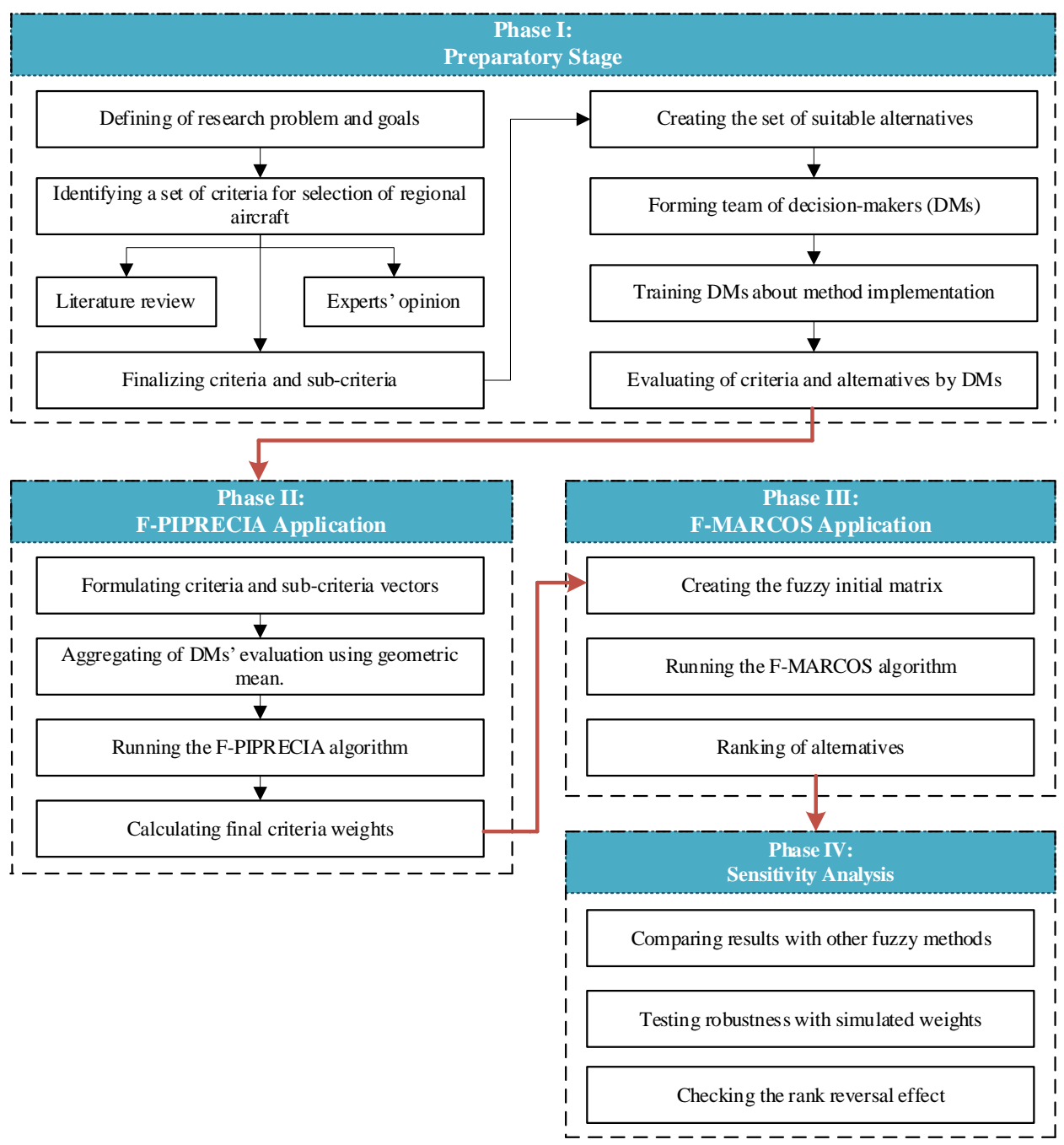

Fig. 1 The phases of the research methodology

Fig. 2 presents the proposed framework based on the aircraft selection literature and expert opinions. All criteria are taken into account as beneficiary types, and considered with the maximization function in this research.

In order to demonstrate the practical applicability of the proposed framework, the airport network in Turkey has been analyzed, and the constraints of the regional aviation system have been determined. In this way, determining feasible aircraft alternatives for the constraints is aimed. The present status of the airports in Turkey is given in Fig. 3. 


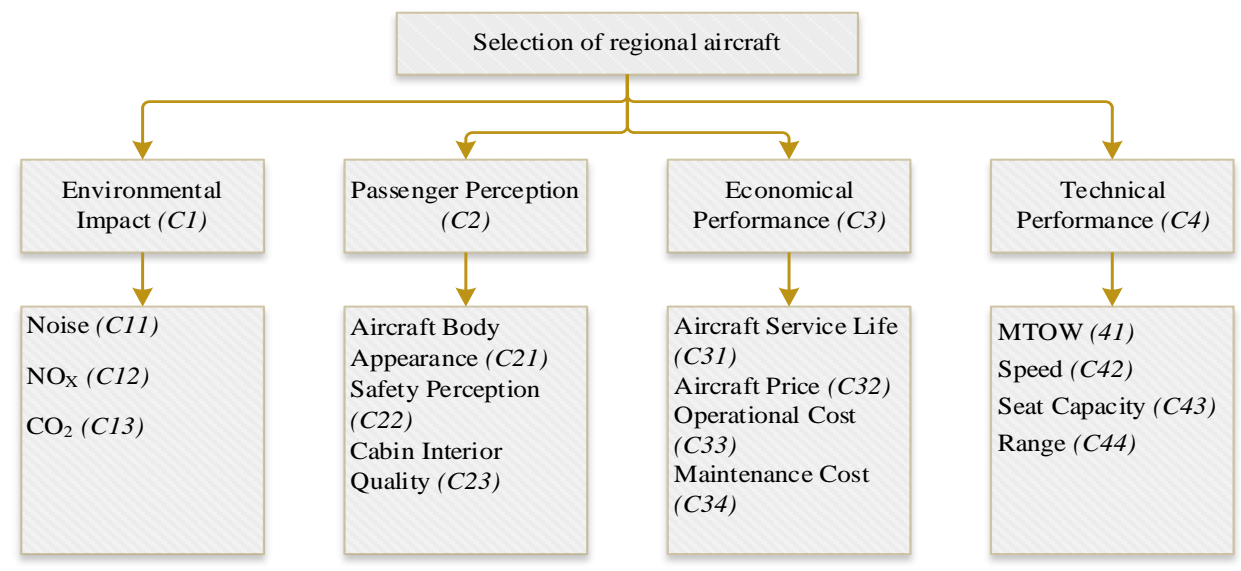

Fig. 2 The proposed framework for regional aircraft selection

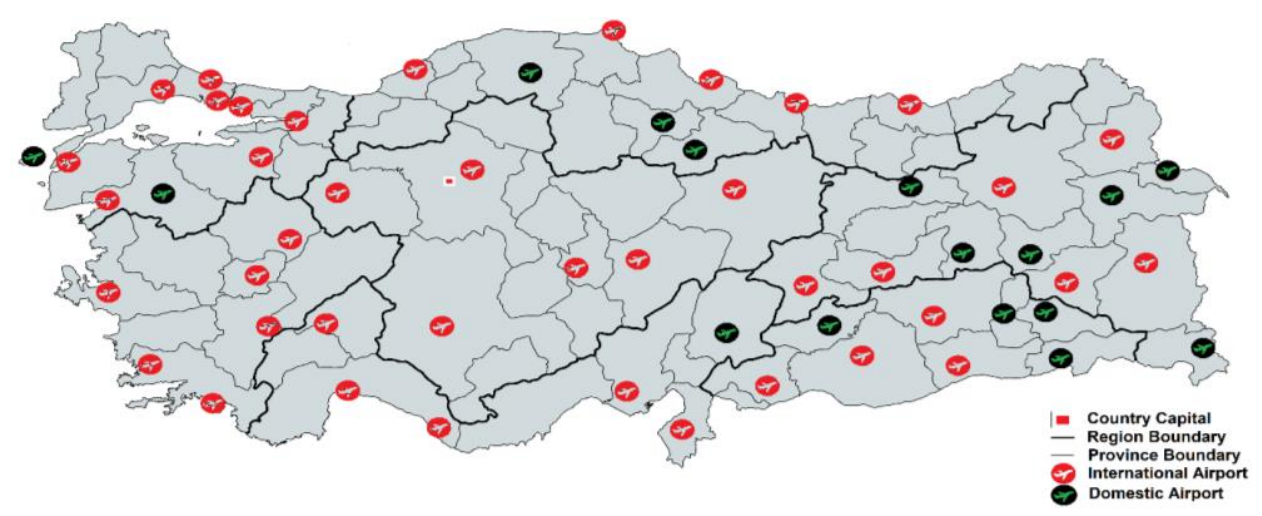

Fig. 3 Present status of airports in Turkey

There are 56 airports in Turkey by the year of 2021. 40 of them are international airports, and the remaining 16 are domestic airports. The distance between the two farthest airports is approximately 1650 kilometers, based on the current state of the airport network. In light of current conditions, aircraft alternatives in the regional aircraft selection problem have been determined to have a minimum range of 1650 kilometers. In addition, taking into account expert opinions based on regional passenger traffic in Turkey, a maximum seat capacity limit of 120 is established for aircraft alternatives. All of the short-haul narrow-body regional aircraft alternatives are compatible for operating at all airports in Turkey in terms of maximum take-off weight (MTOW), maximum landing weight (MLW), and take-off run distance features. In consequence, there are no constraints for operational features such as MTOW, MLW, and take-off run distance.

For building aircraft alternatives set, several aircraft types used for regional aviation purposes in different geographies around the world have been identified. As a result of the examination, Bombardier CRJ1000, ATR 72-600, De Havilland Canada Q400 NextGen, Embraer ERJ-190, Sukhoi SSJ100, Comac ARJ21-700 aircrafts are included in the alternative 
set. Operational characteristics of alternatives have been acquired from the manufacturers' documentations. Economical performance cost data is mainly taken from The Airline Data Project [59]. Emission values of aircraft alternatives vary depending on the engine type and model used. In this context, emission values are taken from ICAO Aircraft Engine Emissions Databank [60], considering the most widely used engine model for each alternative aircraft. Manufacturer documents and various aviation platforms have been consulted for the missing data in the relevant references.

In order to evaluate six aircraft alternatives in line with four main criteria and $14 \mathrm{sub}$ criteria, consisting of five different experts, who are well-informed on airline fleet planning, aircraft selection, and airline management, a DM team was formed. DM team was informed about the criteria, alternatives, and application steps before the evaluation process. The following information was presented to each DM during the evaluation of alternatives: manufacturer company/country, maiden flight date, range $(\mathrm{km})$, cruise speed $(\mathrm{km} / \mathrm{h})$, MTOW (kg), maintenance cost (\$ per block hour), operational cost (\$ per block hour), aircraft price (\$), aircraft service life, CO2 emission (kg per landing/take-off cycle), NOx emission (kg per landing/take-off cycle), noise pollution $(\mathrm{dB})$. In addition, fuselage and cabin photographs of aircraft types were presented so that DMs could evaluate aircraft alternatives from the passenger perspective in line with the passenger perception criteria. The aircraft selection application for the Turkish regional aviation case made based on the comparison data obtained from the evaluations of DMs is presented in the following sections, which correspond to Phase II, Phase III, and Phase IV.

\subsection{F-PIPRECIA results}

In this section, using the responses collected from five DMs, the weights of the criteria and sub-criteria are presented. Because both the F-PIPRECIA and F-MARCOS methods are well-established in the literature, we omitted comprehensive calculation procedures from this paper.

The DMs determined the weights of the criteria and sub-criteria using the linguistic scales in Tables 2 and 3. Accordingly, in the first step of ordinary F-PIPRECIA, each DM compared the main criteria using Eq. (8). Then, as shown in Table 4, an aggregated matrix $\tilde{s}_{j}$ was created by using the geometric mean. Using Eq. (9), $\tilde{s}_{j}$ values were subtracted from the number 2 , thus $\tilde{k}_{j}$ matrix was obtained. In the next step, based on the elements of matrix $\tilde{k}_{j}$, matrix $\tilde{q}_{j}$ was created with the help of Eq. (10). Criteria weights were obtained by using Eq. (11) as the last step of the Ordinary F-PIPRECIA method. In addition, the defuzzified values (DFV) of the criteria weights were given, as Eq. (7) dictates to facilitate the calculation.

The fact that the F-PIPRECIA method produces the final weights of the criteria depends on employing the inverse F-PIPRECIA methodology applied in Eqs. (12)-(15). In contrast to Ordinary F-PIPRECIA, this approach can be accomplished by following the previously mentioned calculation procedures while taking into account the penultimate criterion. Following Eqs. (12)-(15), inverse criteria weights were calculated using Eq. (15) in the last step of the inverse F-PIPRECIA method. These procedures were applied first for the main criteria, and then for the sub-criteria. To use this paper sparingly, this section clarifies only the calculation procedures for the main criteria. Table 5 gives the main criterion weights and the DFV values derived from them. 
Table 5 Weights of the main criteria $(C 1-C 4)$ through F-PIPRECIA

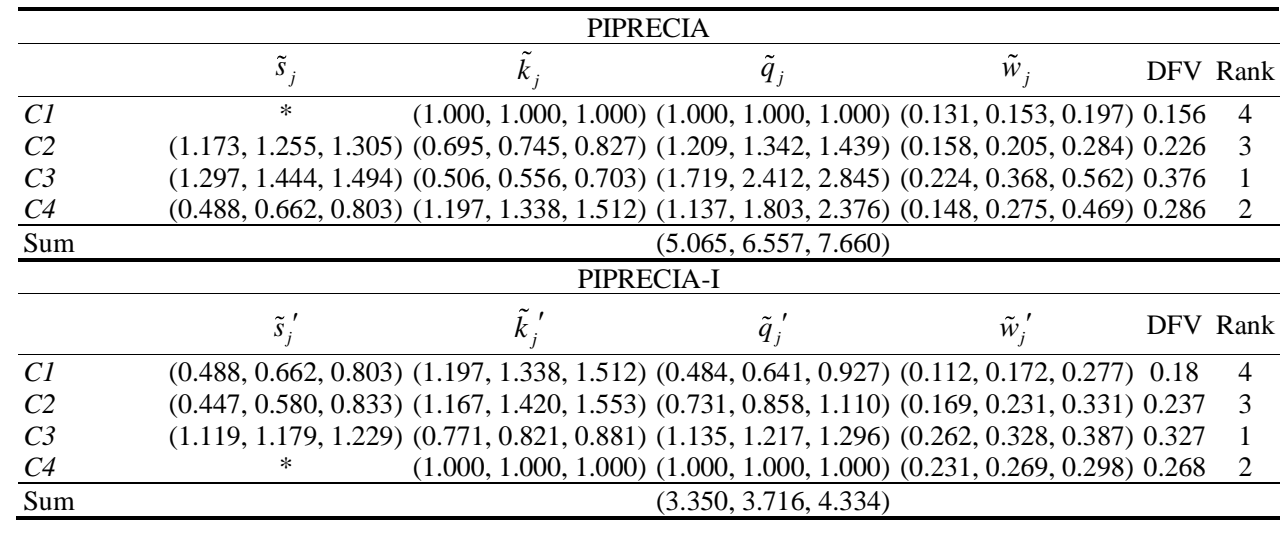

In order to determine the final weights of the criteria, the criteria weights arising from ordinary F-PIPRECIA and inverse F-PIPRECIA applications should be averaged. In this case, the main criterion weights $(C 1-C 4)$ assigned by DMs were found as follows:

$$
w_{C 1}=0.168, \quad w_{C 2}=0.224, \quad w_{C 3}=0.351, \quad w_{C 4}=0.277 \text {. }
$$

The first-order global weights were also calculated in order to transfer the sub-criteria weights to the F-MARCOS application. Table 6 presents the global criteria weights by multiplying the weight of each sub-criterion by the weight of the corresponding main criterion.

Table 6 Final criteria weights derived from the F-PIPRECIA method

\begin{tabular}{|c|c|c|c|c|c|}
\hline Criteria & Criteria weight & Sub-criteria & Local weight & Global weight & Rank \\
\hline \multirow{3}{*}{$C 1$} & \multirow{3}{*}{0.168} & $C 11$ & 0.346 & 0.058 & 12 \\
\hline & & C12 & 0.274 & 0.046 & 14 \\
\hline & & C13 & 0.386 & 0.065 & 11 \\
\hline \multirow{3}{*}{$C 2$} & \multirow{3}{*}{0.224} & $C 21$ & 0.322 & 0.072 & 7 \\
\hline & & $C 22$ & 0.380 & 0.085 & 4 \\
\hline & & $C 23$ & 0.303 & 0.068 & 9 \\
\hline \multirow{4}{*}{ C3 } & \multirow{4}{*}{0.351} & C31 & 0.224 & 0.079 & 5 \\
\hline & & C32 & 0.216 & 0.076 & 6 \\
\hline & & C33 & 0.302 & 0.106 & 1 \\
\hline & & C34 & 0.268 & 0.094 & 2 \\
\hline \multirow{4}{*}{$C 4$} & \multirow{4}{*}{0.277} & C41 & 0.250 & 0.069 & 8 \\
\hline & & $C 42$ & 0.202 & 0.056 & 13 \\
\hline & & C43 & 0.323 & 0.089 & 3 \\
\hline & & C44 & 0.244 & 0.067 & 10 \\
\hline
\end{tabular}

As shown in Table 6, $C_{33}$ (Operational Cost) is the most pivotal criterion in terms of its impact on regional aircraft selection, followed by $C_{34}$ (Maintenance Cost) and $C_{43}$ (Seat Capacity). $C_{12}$ (NOx), on the other hand, is the least important criterion.

Finally, we examined the main criteria and sub-criteria rankings obtained from $\mathrm{F}$ PIPRECIA and inverse F-PIPRECIA application with SRC by using Eq. (30). The SRC 
coefficient is a non-parametric correlation test used when at least one of the variables is not normally distributed or there are no tied ranks [61, 62].

$$
r_{s}=1-\frac{6 \sum d_{i}^{2}}{n\left(n^{2}-1\right)}
$$

where $d_{i}$ is the difference between in the paired ranks and $n$ is the number of cases. Since the SRC coefficient did not fall below 0.80 , the rankings are largely consistent.

\subsection{F-MARCOS results}

Following the determination of the criteria weights, this section employs the FMARCOS approach for selecting regional aircraft alternatives. DMs first evaluated the alternatives by adopting the linguistic scale in described Table 4 . Table 7 shows the fuzzy aggregated decision matrix formed as a result of the judgments of five DMs. In the aggregation process, the arithmetic average was used due to the nature of the judgments.

Table 7 Fuzzy aggregated decision matrix

\begin{tabular}{lccccc}
\hline & C11 & C12 & $\ldots$ & C43 & C44 \\
\hline CRJ1000 & $(5.40,7.20,8.40)$ & $(4.20,6.20,7.80)$ & $\ldots$ & $(6.20,7.80,9.00)$ & $(6.60,8.40,9.40)$ \\
ATR 72-600 & $(5.80,7.80,9.20)$ & $(5.80,7.80,9.40)$ & $\ldots$ & $(1.60,3.40,5.40)$ & $(1.60,3.40,5.40)$ \\
Q400 NextGen & $(4.20,6.20,7.80)$ & $(5.40,7.40,8.80)$ & $\ldots$ & $(3.80,5.80,7.60)$ & $(4.20,6.20,8.20)$ \\
ERJ-190 & $(3.80,5.80,7.40)$ & $(1.40,2.60,4.40)$ & $\ldots$ & $(7.80,9.20,9.80)$ & $(8.20,9.40,9.80)$ \\
SSJ100 & $(5.80,7.60,8.80)$ & $(5.00,7.00,8.80)$ & $\ldots$ & $(5.40,7.40,9.00)$ & $(6.60,8.40,9.40)$ \\
ARJ21-700 & $(5.80,7.80,9.20)$ & $(5.40,7.40,9.00)$ & $\ldots$ & $(2.60,4.60,6.60)$ & $(4.60,6.60,8.40)$ \\
\hline
\end{tabular}

Then, using Eqs. (17)-(18), the fuzzy aggregated evaluation matrix was extended to include fuzzy ideal $\tilde{A}(I D)$ and fuzzy anti-ideal $\tilde{A}(A I)$ solutions. In the study, since all criteria are used as beneficial criteria due to the structure of the linguistic scale, $\tilde{A}(I D)$ represents the most desirable and $\tilde{A}(A I)$ represents the most undesirable values. Moreover, the extended fuzzy initial decision matrix was normalized by applying Eqs. (19)-(20) (Table 8).

Table 8 Fuzzy normalized decision matrix

\begin{tabular}{lccccc}
\hline & C11 & C12 & $\ldots$ & C43 & C44 \\
\hline AI & $(0.41,0.63,0.80)$ & $(0.15,0.28,0.47)$ & $\ldots$ & $(0.16,0.35,0.55)$ & $(0.16,0.35,0.55)$ \\
CRJ1000 & $(0.59,0.78,0.91)$ & $(0.45,0.66,0.83)$ & $\ldots$ & $(0.63,0.80,0.92)$ & $(0.67,0.86,0.96)$ \\
ATR 72-600 & $(0.63,0.85,1.00)$ & $(0.62,0.83,1.00)$ & $\ldots$ & $(0.16,0.35,0.55)$ & $(0.16,0.35,0.55)$ \\
Q400 NextGen & $(0.46,0.67,0.85)$ & $(0.57,0.79,0.94)$ & $\ldots$ & $(0.39,0.59,0.78)$ & $(0.43,0.63,0.84)$ \\
ERJ-190 & $(0.41,0.63,0.80)$ & $(0.15,0.28,0.47)$ & $\ldots$ & $(0.80,0.94,1.00)$ & $(0.84,0.96,1.00)$ \\
SSJ100 & $(0.63,0.83,0.96)$ & $(0.53,0.74,0.94)$ & $\ldots$ & $(0.55,0.76,0.92)$ & $(0.67,0.86,0.96)$ \\
ARJ21-700 & $(0.63,0.85,1.00)$ & $(0.57,0.79,0.96)$ & $\ldots$ & $(0.27,0.47,0.67)$ & $(0.47,0.67,0.86)$ \\
ID & $(0.63,0.85,1.00)$ & $(0.62,0.83,1.00)$ & $\ldots$ & $(0.80,0.94,1.00)$ & $(0.84,0.96,1.00)$ \\
\hline
\end{tabular}

Following that, the criteria weights obtained from the F-PIPRECIA application were included in the calculation. Using Eq. (21), the fuzzy normalized decision matrix elements were multiplied by their respective criterion weights. The fuzzy weighted normalized decision matrix created is shown in Table 9. 
Table 9 Fuzzy weighted normalized decision matrix

\begin{tabular}{lccccc}
\hline & $\mathrm{C} 11$ & $\mathrm{C} 12$ & $\ldots$ & $\mathrm{C} 43$ & $\mathrm{C} 44$ \\
\hline AI & $(0.02,0.04,0.05)$ & $(0.01,0.01,0.02)$ & $\ldots$ & $(0.01,0.03,0.05)$ & $(0.01,0.02,0.04)$ \\
CRJ1000 & $(0.03,0.05,0.05)$ & $(0.02,0.03,0.04)$ & $\ldots$ & $(0.06,0.07,0.08)$ & $(0.05,0.06,0.06)$ \\
ATR 72-600 & $(0.04,0.05,0.06)$ & $(0.03,0.04,0.05)$ & $\ldots$ & $(0.01,0.03,0.05)$ & $(0.01,0.02,0.04)$ \\
Q400 NextGen & $(0.03,0.04,0.05)$ & $(0.03,0.04,0.04)$ & $\ldots$ & $(0.03,0.05,0.07)$ & $(0.03,0.04,0.06)$ \\
ERJ-190 & $(0.02,0.04,0.05)$ & $(0.01,0.01,0.02)$ & $\ldots$ & $(0.07,0.08,0.09)$ & $(0.06,0.06,0.07)$ \\
SSJ100 & $(0.04,0.05,0.06)$ & $(0.02,0.03,0.04)$ & $\ldots$ & $(0.05,0.07,0.08)$ & $(0.05,0.06,0.06)$ \\
ARJ21-700 & $(0.04,0.05,0.06)$ & $(0.03,0.04,0.04)$ & $\ldots$ & $(0.02,0.04,0.06)$ & $(0.03,0.05,0.06)$ \\
ID & $(0.04,0.05,0.06)$ & $(0.03,0.04,0.05)$ & $\ldots$ & $(0.07,0.08,0.09)$ & $(0.06,0.06,0.07)$ \\
\hline
\end{tabular}

Following the weighting procedure, fuzzy summation matrix $\left(\tilde{S}_{i}\right)$ was created by applying Eq. (22). One of the unique elements of the F-MARCOS method is the utility degree. Therefore, using Eqs. (23)-(24), $\tilde{K}_{i}^{-}$and $\tilde{K}_{i}^{+}$matrices, which are utility degrees according to ideal and anti-ideal solutions, were constructed. Then, a fuzzy matrix $\tilde{T}_{i}$ is created by summing the utility degrees with the help of Eq. (25). Moreover, an FMARCOS-specific fuzzy number $(\tilde{D})$ is derived from this matrix using Eq. (26). However, it should be noted that this new and all fuzzy values obtained after this step will be defuzzified by using Eq. (7).

Based on defuzzified value $d f_{\text {crisp }}$, ideal $f\left(\tilde{K}_{i}^{+}\right)$and anti-ideal $f\left(\tilde{K}_{i}^{-}\right)$solutions were obtained using Eqs. (27)-(28) in the next step. As mentioned earlier, $\tilde{K}_{i}^{-}, \tilde{K}_{i}^{+}, f\left(\tilde{K}_{i}^{-}\right)$ and $f\left(\tilde{K}_{i}^{+}\right)$values suggested by the F-MARCOS method were defuzzified by applying Eq. (7) to create the $f\left(K_{i}\right)$ vector. The finalized F-MARCOS results and observed ranking are shown in Table 10.

Table 10 Defuzzified values and results of F-MARCOS application

\begin{tabular}{lcccccccc}
\hline & $f\left(\tilde{K}_{i}^{-}\right)$ & $f\left(\tilde{K}_{i}^{+}\right)$ & $K_{i}^{-}$ & $K_{i}^{+}$ & $f\left(K_{i}^{-}\right)$ & $f\left(K_{i}^{+}\right)$ & $f\left(K_{i}\right)$ & Rank \\
\hline CRJ1000 & $(0.20,0.29,0.42)$ & $(0.32,0.64,1.35)$ & 2.05 & 0.86 & 0.30 & 0.70 & 0.77 & 1 \\
ATR 72-600 & $(0.15,0.24,0.37)$ & $(0.24,0.52,1.19)$ & 1.71 & 0.71 & 0.24 & 0.59 & 0.50 & 6 \\
Q400 NextGen & $(0.15,0.24,0.38)$ & $(0.24,0.52,1.20)$ & 1.71 & 0.71 & 0.24 & 0.59 & 0.51 & 5 \\
ERJ-190 & $(0.19,0.27,0.39)$ & $(0.31,0.60,1.25)$ & 1.92 & 0.81 & 0.28 & 0.66 & 0.67 & 4 \\
SSJ100 & $(0.19,0.28,0.42)$ & $(0.31,0.62,1.33)$ & 2.00 & 0.84 & 0.29 & 0.68 & 0.72 & 2 \\
ARJ21-700 & $(0.18,0.27,0.41)$ & $(0.30,0.60,1.32)$ & 1.96 & 0.82 & 0.28 & 0.67 & 0.69 & 3 \\
\hline
\end{tabular}

As shown in Table 10, the best-ranked alternative was found as CRJ1000. That is, CRJ1000 is the most promising aircraft type for regional flights in the Turkish airline industry. In contrast, it is observed that the worst-performing alternative was identified ATR 72-600, with the lowest utility function.

\subsection{Sensitivity analysis}

The credibility and robustness of the results depend on how resistant they are to changes in input parameters. Therefore, this section is devoted to validating the results employing a threefold rigorous sensitivity analysis. In the first part, we tested the effect of changing criteria weights on the results using simulated weights. Using Eq. (31), we generated 25 scenarios based on the most critical criterion $C_{33}$ [50, 63-65]. 


$$
w_{n \beta}=\left(1-w_{n \alpha}\right) \frac{w_{\beta}}{\left(1-w_{n}\right)}
$$

In that formula, $w_{n} \beta$ denotes the scenario-adjusted weights of the criteria, and $w_{n} \alpha$ reflects the reduced values of the most important criterion $\left(C_{33}\right)$. $w_{\beta}$ denotes the original weight assigned to the marked criteria, while $w_{n}$ is the original weight of the most important criterion $\left(C_{33}\right)$ [66]. At this point, the rate of reduction in $w_{n \alpha}$ was determined as $4 \%$. The weight scenarios generated are shown in Fig. 4. Furthermore, scenario-based application rankings are portrayed in Fig. 5. In scenario-based rankings, the lowest level of SRC was measured as 0.829 , thus achieving a high level of consistency.

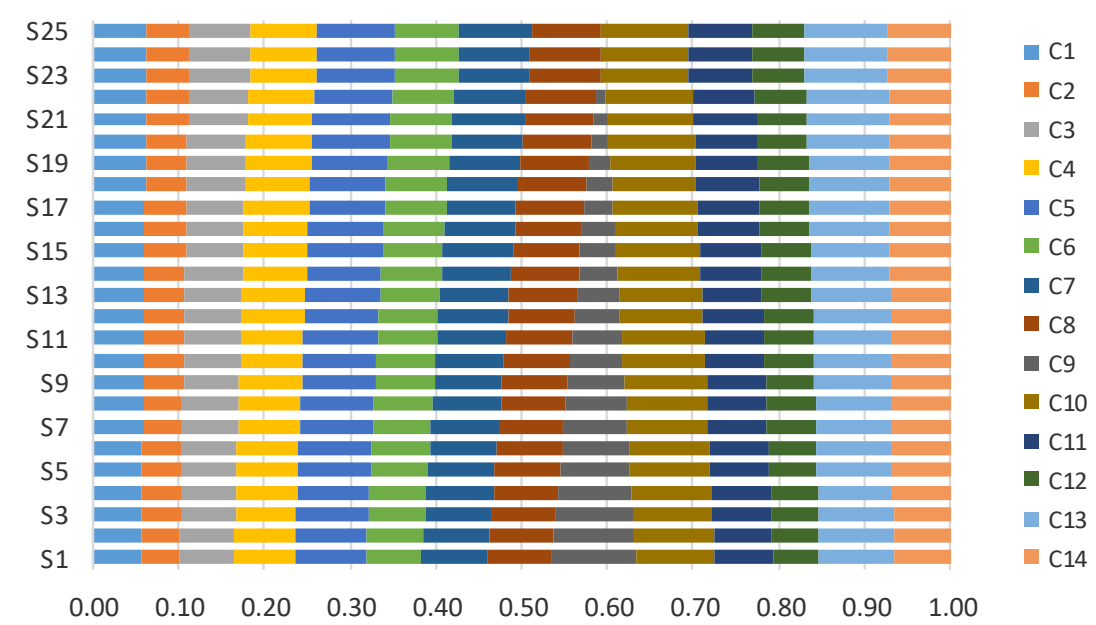

Fig. 4 Weights of criteria through 25 scenarios

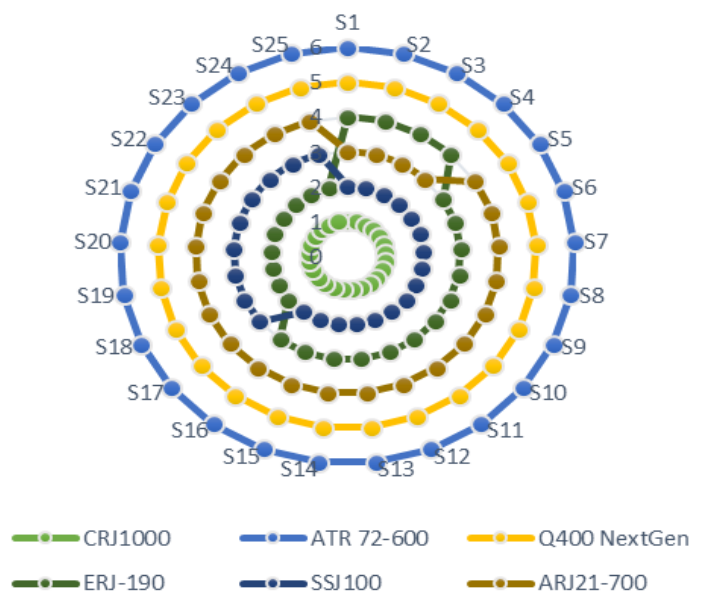

Fig. 5 Alternative rankings generated through 25 scenarios 
In the second part, F-MARCOS findings were compared to those obtained using seven well-established fuzzy-based MCDM techniques [67]. Fig. 6 illustrates the effects of the comparative analysis through a correlation map. As a result, the lowest SRC between FMARCOS and the outcomes of other techniques is 0.943 , indicating that the rankings are almost identical and the implementation is satisfactorily credible.

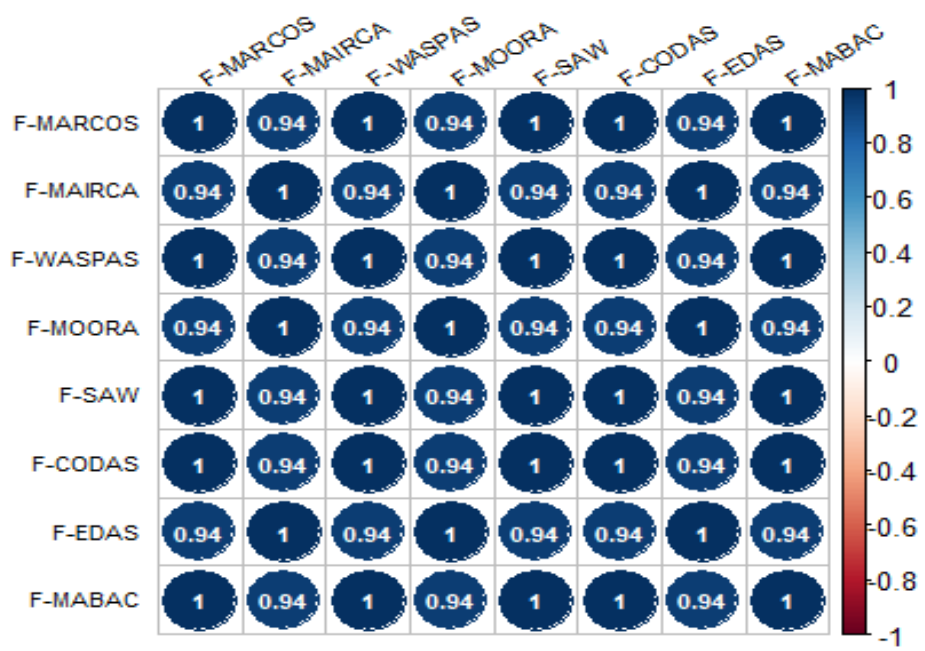

Fig. 6 Comparative results of different fuzzy-based MCDM methods

In the last part, any rank reversal risk was checked considering the matrix size [68]. In doing so, the application is continued until the last alternative remains by eliminating the worst listed criteria in each scenario. We tested the rank reversal effect in five scenarios. As shown in Fig. 7, there is no change in the rankings, and the results gave quite stable results. In summary, the results of the three-stage rigorous sensitivity analysis established the credibility and robustness of the application.

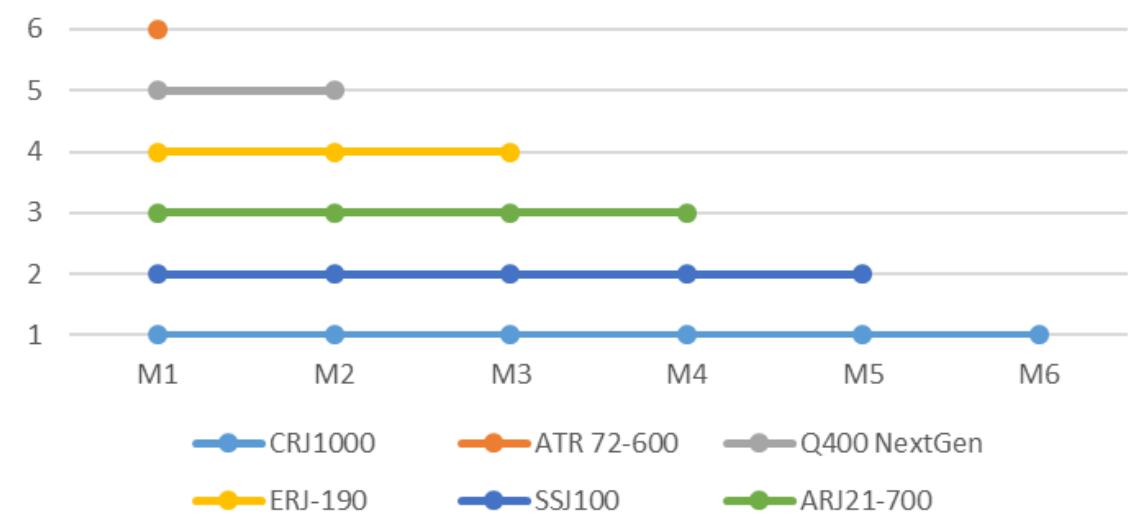

Fig. 7 Scenario results on rank reversal test 


\section{CONCLUSION}

Fleet planning, one of the most important strategic decisions made by airlines, has a significant impact on airline productivity and efficiency [69]. Selecting the most suitable aircraft type for the airline's business model and business strategies is an important step in the fleet planning process [70]. Regional airlines, on the other hand, differ from other airline business models in terms of flight operation characteristics. Some of these are features such as having cross flights, low passenger volume, feeding certain hubs, code-sharing with major airlines [71]. The unique characteristics of regional airlines require different approaches to the aircraft selection problem from other business models. Although the criteria sets of many aircraft selection problems are similar, criteria weights change according to the airline business model.

Focusing on the Turkish airline industry, this study revealed that the most important criterion in aircraft selection is operational cost $\left(C_{33}\right)$. The second and third most important criteria are maintenance cost $\left(C_{34}\right)$ and seat capacity $\left(C_{43}\right)$, respectively. Among the main criteria, the most important regional aircraft selection criterion was determined as economic performance $\left(C_{3}\right)$. The results corroborate previous research in which economical efficiency was a significant factor in aircraft selection [9, 26, 31]. On the other hand, technical performance $\left(C_{4}\right)$ ranked second. Passenger perception $\left(C_{2}\right)$ and environmental impact $\left(C_{l}\right)$ came third and last, respectively. In addition, it was found out that the importance of the passenger perception criterion, which is evaluated for the first time within the scope of the aircraft selection problem, is very close to the technical performance. Specifically, according to global criterion weights, safety perception $\left(C_{22}\right)$ was found as the fourth most important criterion. In this regard, the study contributes to the literature by proposing a framework regarding regional aircraft selection and evaluating passenger perceptions in this framework.

In terms of managerial contributions, the study offers valuable insights for regional airline managers in the Turkish airline industry, which continues to grow rapidly. The implementation of regional aircraft selection, which is considered within the current state of the country's aviation, reveals the criteria that the industry should pay attention to. It is also seen that the CRJ1000 is the most preferable aircraft type among alternatives. Lastly, the approach employed yields consistent results within the case study.

Despite its novelty, this study has some limitations. There are many constraints and criteria that affect the aircraft selection problem, which is very complex. In this study, the regional aviation problem has been discussed in the case of the Turkish airline industry. The findings cannot be generalized to all regional aviation activities around the world. In future studies, the present framework can be expanded, and different cases can be approached. Moreover, future studies can contribute to the literature by including the passenger perception criterion into aircraft selection applications for different airline business models. Finally, it is suggested to address the regional aircraft selection problem by using different fuzzy sets such as Pythagorean, neutrosophic, and spherical numbers.

\section{REFERENCES}

1. Wang, J., Yang, H., Wang, H., 2019, The evolution of China's international aviation markets from a policy perspective on air passenger flows, Sustainability, 11, pp. 1-15.

2. IATA, 2020, Air Passenger Forecasts Global Report, Retrieved from https://go.updates.iata.org///123902/2019-0517/837vbs (last access: 10.04.2021) 
3. ICAO, 2018, Global Air Transport Outlook to 2030 and trends to 2040, Retrieved from https://www.icao. int/sustainability/Pages/GATO2030.aspx (last access: 03.04.2021)

4. Sarlgan, A.E., 2011, The Requirements of Developing The Regional Airline Transportation in Turkey, Anadolu University Journal of Social Sciences, 11, pp. 69-88

5. Dožić, S., Kalić, M., 2015, Comparison of two MCDM methodologies in aircraft type selection problem, Transportation Research Procedia, 10, pp. 910-919.

6. Lourenzutti, R., Krohling, R.A., 2014, The Hellinger distance in Multicriteria Decision Making: An illustration to the TOPSIS and TODIM methods, Expert Systems with Applications 41, pp. 4414-4421.

7. Ahmed, S.K., Sivakumar, G., Kabir, G., Ali, S.M., 2020, Regional aircraft selection integrating fuzzy analytic hierarchy process (FAHP) and efficacy method, Journal of Production Systems \& Manufacturing Science, pp. 63-86.

8. Dožić, S., Lutovac, T., Kalić, M., 2018, Fuzzy AHP approach to passenger aircraft type selection, Journal of Air Transport Management, 68, pp. 165-175.

9. Kirac1, K., Akan, E., 2020, Aircraft selection by applying AHP and TOPSIS in interval type-2 fuzzy sets, Journal of Air Transport Management, 89, 101924.

10. Puška, A., Pamucar, D., Stojanović, I., Cavallaro, F., Kaklauskas, A., Mardani, A., 2021, Examination of the sustainable rural tourism potential of the brčko district of bosnia and herzegovina using a fuzzy approach based on group decision making, Sustainability, 13, pp. 1-23.

11. Stević, Ž., Stjepanović, Ž., Božičković, Z., Das, D.K., Stanujkić, D., 2018, Assessment of conditions for implementing information technology in a warehouse system: A novel fuzzy PIPRECIA method, Symmetry, 10,586 .

12. Boral, S., Howard, I., Chaturvedi, S.K., McKee, K., Naikan, V.N.A., 2020, An integrated approach for fuzzy failure modes and effects analysis using fuzzy AHP and fuzzy MAIRCA, Engineering Failure Analysis, 108, pp. $1-16$.

13. Embraer, 2020, Market Outlook 2019-2038, Retrieved from https://www.embraermarketoutlook2020.com (last access: 22.04.2021)

14. The World Bank, Air transport, passengers carried, Retrieved from https://data.worldbank.org/indicator/ IS.AIR.PSGR (last access: 27.03.2021)

15. Merkert, R., Beck, M., 2017, Value of travel time savings and willingness to pay for regional aviation, Transportation Research Part A: Policy and Practice, 96, pp. 29-42.

16. Embraer, 2021, E195, Retrieved from https://www.embraercommercialaviation.com/commercial-jets/e195/ (last access: 12.04 .2021$)$

17. Forbes, S.J., Lederman, M., 2007, The role of regional airlines in the US airline industry, The Economics of Airline Institutions, Operations and Marketing, 2, pp. 193-208.

18. Levine, M.E., 2011, Regulation and the Nature of the Firm: The Case of U.S. Regional Airlines, The Journal of Law and Economics, 54, pp. 229-248.

19. Ilgin, M.A., 2019, Aircraft Selection Using Linear Physical Programming. Journal of Aeronautics and Space Technologies, 12, pp. 121-128.

20. Ali, Y., Asghar, A., Muhammad, N., Salman, A., 2017, Selection of a Fighter Aircraft To Improve the Effectiveness of Air Combat in the War on Terror: Pakistan Air Force - A Case in Point, International Journal of the Analytic Hierarchy Process, 9.

21. Van Hoan, P., Ha, Y., 2020, ARAS-fucom approach for VPAF fighter aircraft selection, Decision Science Letters, 10, pp. 53-62.

22. Durmaz, K.I.., Gencer, C., 2020, A new plugin based on JSMAA: SWARA-JSMAA and aerobatic aircraft selection, Journal of the Faculty of Engineering and Architecture of Gazi University, 3, pp. 1487-1498.

23. Wang, T.C., Chang, T.H., 2007, Application of TOPSIS in evaluating initial training aircraft under a fuzzy environment, Expert Systems with Applications, 33, pp. 870-880.

24. Sánchez-Lozano, J.M., Serna, J., Dolón-Payán, A., 2015, Evaluating military training aircrafts through the combination of multi-criteria decision making processes with fuzzy logic. A case study in the Spanish Air Force Academy, Aerospace Science and Technology, 42, pp. 58-65.

25. Kiracı, K., Bakır, M., 2018, Application of Commercial Aircraft Selection in Aviation Industry Through MultiCriteria Decision Making Methods, Manisa Celal Bayar University Journal of Social Sciences, 16, pp. 307-332.

26. Bruno, G., Esposito, E., Genovese, A., 2015, A model for aircraft evaluation to support strategic decisions, Expert Systems with Applications, 42, pp. 5580-5590.

27. Akyurt, İ.Z., Kabadayı, N., 2020, Fuzzy AHP and Fuzzy Grey Relational Method for Cargo Aircraft Type Selection: A Case Study in a Turkish Airline Company, Journal of Yaşar University, 15, pp. 38-55.

28. Sun, X., Gollnick, V., Stumpf, E., 2011, Robustness Consideration in Multi-Criteria Decision Making to an Aircraft Selection Problem, Journal of Multi-Criteria Decision Analysis, 18, pp. 55-64. 
29. Ozdemir, Y., Basligil, H., 2016, Aircraft selection using fuzzy ANP and the generalized choquet integral method: The Turkish airlines case, Journal of Intelligent and Fuzzy Systems, 31, pp. 589-600.

30. Yeh, C.H., Chang, Y.H., 2009, Modeling subjective evaluation for fuzzy group multicriteria decision making, European Journal of Operational Research, 194, pp. 464-473.

31. Gomes, L.F.A.M., De Mattos Fernandes, J.E., De Mello, J.C.C.B.S., 2014, A fuzzy stochastic approach to the multicriteria selection of an aircraft for regional chartering, Journal of Advanced Transportation, 48, pp. 223-237.

32. Ozdemir, Y., Basligil, H., Karaca, M., 2011, Aircraft selection using Analytic Network Process: A case for Turkish Airlines, Proc. of the World Congress on Engineering 2011, London, pp. 1155-1159.

33. Sánchez-Lozano, J.M., Rodríguez, O.N., 2020, Application of Fuzzy Reference Ideal Method (FRIM) to the military advanced training aircraft selection, Applied Soft Computing, 88, 106061.

34. Stanujkic, D., Karabasevic, D., Zavadskas, E.K., 2015, A framework for the selection of a packaging design based on the SWARA method, Engineering Economics, 26, pp. 181-187.

35. Zadeh, L.A., 1965, Fuzzy sets, Information and Control, 8, pp. 338-353.

36. Popović, G., Stanujkić, D., Karabašević, D., Štirbanović, Z., 2020, Model for ore deposits selection by using the fuzzy TOPSIS method, Journal of Mining and Metallurgy A: Mining, 56, pp. 59-71.

37. Stanković, M., Stević, Ž., Das, D.K., Subotić, M., Pamucar, D., 2020, A New Fuzzy MARCOS Method for Road Traffic Risk Analysis, Mathematics, 8, pp. 1-18.

38. Vrtagić, S., Softić, E., Subotić, M., Stević, Ž., Dordevic, M., Ponjavic, M., 2021, Ranking Road Sections Based on MCDM Model: New Improved Fuzzy SWARA (IMF SWARA), Axioms, 10(92), pp. 1-23.

39. Pamucar, D., Ecer, F., 2020, Prioritizing the Weights of the Evaluation Criteria Under Fuzziness: The Fuzzy Full Consistency Method - FUCOM-F, Facta Universitatis-Series Mechanical Engineering, 18, pp. 419-437.

40. Stanujkic, D., Zavadskas, E.K., Karabasevic, D., Smarandache, F., Turskis, Z., 2017, The use of the pivot pairwise relative criteria importance assessment method for determining the weights of criteria, Romanian Journal of Economic Forecasting, 20, pp. 116-133.

41. Vesković, S., Milinković, S., Abramović, B., Ljubaj, I., 2020, Determining Criteria Significance in Selecting Reach Stackers by Applying the Fuzzy PIPRECIA Method, Operational Research in Engineering Sciences: Theory and Applications, 3, pp. 72-88.

42. Memiș, S., Demir, E., Karamașa, C., Korucuk, S., 2020, Prioritization of road transportation risks: An application in Giresun province, Operational Research in Engineering Sciences: Theory and Applications, 3, pp. 111-126.

43. Đalić, I., Stević, Ž., Karamasa, C., Puška, A., 2020, A Novel Integrated Fuzzy PIPRECIA-Interval Rough Saw Model: Green Supplier Selection, Decision Making: Applications in Management and Engineering, 3, pp. 80-95.

44. Blagojević, A., Kasalica, S., Stević, Ž., Tričkovič, G., Pavelkić, V., 2021, Evaluation of safety degree at railway crossings in order to achieve sustainable traffic management: A novel integrated fuzzy MCDM model, Sustainability, 13, pp. 1-20.

45. Tomaševic, M., Lapuh, L., Stevic, Ž., Stanujkic, D., Karabaševic, D., 2020, Evaluation of criteria for the implementation of high-performance computing (HPC) in danube region countries using fuzzy piprecia method, Sustainability, 12, pp. 1-18.

46. Stević, Ž., Pamucar, D., Puška, A., Chatterjee, P., 2020, Sustainable supplier selection in healthcare industries using a new MCDM method: Measurement of alternatives and ranking according to COmpromise solution (MARCOS), Computers and Industrial Engineering, 140, 106231.

47. Mijajlović, M., Puška, A., Stević, Ž., Marinković, D., Doljanica, D., Jovanović, S.V., Stojanović, I., Beširović, J., 2020, Determining the competitiveness of spa-centers in order to achieve sustainability using a fuzzy multicriteria decision-making model, Sustainability, 12, pp. 1-17.

48. Puška, A., Stević, Ž., Stojanović, I., 2021, Selection of Sustainable Suppliers Using the Fuzzy MARCOS Method, Current Chinese Science, 1, pp. 1-12.

49. Badi, I., Pamucar, D., 2020, Supplier selection for steelmaking company by using combined Grey-MARCOS methods, Decision Making: Applications in Management and Engineering, 3, pp. 37-48.

50. Mitrović Simić, J., Stević, Ž., Zavadskas, E.K., Bogdanović, V., Subotić, M., Mardani, A., 2020, A Novel CRITIC-Fuzzy FUCOM-DEA-Fuzzy MARCOS Model for Safety Evaluation of Road Sections Based on Geometric Parameters of Road, Symmetry, 12(12), pp. 1-27.

51. Tsiotas, D., Erdem, U., Cubukcu, K.M., 2020, Outlining the historical framework of the aviation sector in Turkey: A spatiotemporal approach, Regional Statistics, 10, pp. 117-141.

52. Sivrikaya, O., Tunc, E., 2013, Demand Forecasting for Domestic Air Transportation in Turkey, The Open Transportation Journal, 7, pp. 20-26.

53. Tomová, A., Materna, M., 2018, Miscellaneous “modi vivendi” of regional and network airlines: The tracks for future research, Transportation Research Procedia, 35, pp. 305-314. 
54. Dožić, S., Kalić, M., 2018, Aircraft Type Selection Problem: Application of Different MCDM Methods, Advances in Intelligent Systems and Computing, pp. 156-175.

55. Sultan, F., Simpson, M.C., 2000, International service variants: airline passenger expectations and perceptions of service quality, Journal of Services Marketing, 14(3), pp. 188-216.

56. Ahmadpour, N., Lindgaard, G., Robert, J.M., Pownall, B., 2014, The thematic structure of passenger comfort experience and its relationship to the context features in the aircraft cabin, Ergonomics, 57(6), pp. 801-815.

57. Jeeradist, T., Thawesaengskulthai, N., Sangsuwan, T., 2016, Using TRIZ to enhance passengers' perceptions of an airline's image through service quality and safety, Journal of Air Transport Management, 53, pp. 131-139.

58. Chang, Y.H., Yeh, C.H., 2002, A survey analysis of service quality for domestic airlines, European Journal of Operational Research, 139, pp. 166-177.

59. MIT Global Airline Industry Program, n.d., The Airline Data Project, Retrieved from http://web.mit.edu/ airlinedata/www/default.html (last access: 25.03.2021)

60. ICAO, 2021, ICAO Aircraft Engine Emissions Databank.

61. Pamučar, D., Savin, L., 2020, Multiple-criteria model for optimal off-road vehicle selection for passenger transportation: BWM-COPRAS model, Vojnotehnicki glasnik, 68, pp. 28-64.

62. Bobar, Z., Božanić, D., Djurić, K., Pamučar, D., 2020, Ranking and Assessment of the Efficiency of Social Media using the Fuzzy AHP-Z Number Model - Fuzzy MABAC, Acta Polytechnica Hungarica, 17, pp. 43-70.

63. Torkayesh, A.E., Hashemkhani Zolfani, S., Kahvand, M., Khazaelpour, P., 2021, Landfill location selection for healthcare waste of urban areas using hybrid BWM-grey MARCOS model based on GIS, Sustainable Cities and Society, 67, 102712.

64. Yazdani, M., Torkayesh, A.E., Santibanez-Gonzalez, E.D., Otaghsara, S.K., 2020, Evaluation of renewable energy resources using integrated Shannon Entropy - EDAS model, Sustainable Operations and Computers, 1, pp. $35-42$.

65. Torkayesh, A.E., Ecer, F., Pamucar, D., Karamaşa, C., 2021, Comparative assessment of social sustainability performance: Integrated data-driven weighting system and CoCoSo model, Sustainable Cities and Society, 71, 102975.

66. Stević, Ž., Karamaşa, Ç., Demir, E., Korucuk, S., 2021, Assessing sustainable production under circular economy context using a novel rough-fuzzy MCDM model: A case of the forestry industry in the Eastern Black Sea region, Journal of Enterprise Information Management, ahead-of-print.

67. Torkayesh, A.E., Pamucar, D., Ecer, F., Chatterjee, P., 2021, An integrated BWM-LBWA-CoCoSo framework for evaluation of healthcare sectors in Eastern Europe, Socio-Economic Planning Sciences, 101052.

68. Vesković, S., Stević, Ž., Karabašević, D., Rajilić, S., Milinković, S., Stojić, G., 2020, A new integrated fuzzy approach to selecting the best solution for business balance of passenger rail operator: Fuzzy PIPRECIA-fuzzy EDAS model, Symmetry, 12, pp. 1-20.

69. Merkert, R., Hensher, D.A., 2011, The impact of strategic management and fleet planning on airline efficiency A random effects tobit model based on DEA efficiency scores, Transportation Research Part A: Policy and Practice, 45, pp. 686-695.

70. Dožić, S., Kalić, M., 2015, Three-stage airline fleet planning model, Journal of Air Transport Management, 46, pp. 30-39.

71. Truitt, L.J., Haynes, R., 1994, Evaluating Service Quality and Productivity in the Regional Airline Industry, Transportation Journal, 33, pp. 21-32. 